\title{
Physician age and patient outcomes
}

\author{
(ㄷ) $(1) \Theta$ OPEN ACCESS \\ New research reports a link, but the underlying mechanism remains unclear
}

\section{Linda H Aiken Claire M Fagin leadership professor of nursing, Joshua H Dahlerbruch research fellow}

Center for Health Outcomes and Policy Research, School of Nursing, University of Pennsylvania, 418 Curie Boulevard, 387R Philadelphia, PA 19104-4217, USA

Advances in research on patient outcomes and greater availability of detailed standardized administrative data on healthcare outcomes, particularly for patients admitted to hospital, enable examination of the performance of providers and health systems from new perspectives. In a linked paper, Tsugawa and colleagues (doi:10.1136/bmj.j1797) devised a creative research design to exploit these resources to take a fresh and informative look at the association between physician age and patient outcomes with reference to 30 day hospital mortality, readmissions, and medical care costs. ${ }^{1}$

Their focus was a US national sample of elderly Medicare patients with serious medical illnesses who required admission to hospital and whose care was provided by a hospitalist physician, defined as a general internist who filed at least $90 \%$ of total "evaluation and management" billings in an inpatient hospital. The hospitalist in the US is a relatively new medical specialty since the mid-1990s. ${ }^{2}$ Within any given hospital, patients treated by a specific hospitalist, the authors argue, are "plausibly quasi-randomized" by patients' time of admission and hospitalists' work hours. Additionally, patient risk factors and time of admission that could signify higher illness acuity are controlled analytically. Comparison within a hospital of hospitalists' patient outcomes is a strategy for controlling by design for hospital level factors that could be associated with patient outcomes.

Tsugawa and colleagues showed that patients of older hospitalists had higher odds of 30 day in hospital mortality than patients of younger hospitalists, except for hospitalists with high volumes of patients, where no association of physician age and mortality was found. ${ }^{1}$ They found no association between hospitalist age and patient readmission. Older hospitalists had slightly higher billings.

In the US context, age of hospitalist could reflect cohort selection effects into a new specialty and education differences over time as the specialty evolved. Replication in a different international context-like the UK, where hospital based physicians have long been the norm—would be useful. Recent advances in patient matching, ${ }^{3}$ exploiting the large administrative patient databases now available in many countries, are also worth investigating as a different strategy to account for any confounding of higher severity of illness with more senior physician status and age.

While a single study rarely provides definitive answers to complex questions, this one succeeds with new considerations about an old topic - namely, if provider age is associated with clinical performance, what are the options for ensuring that quality and safety of care is optimized for patients? The within hospital design of this study is useful in controlling for hospital level differences that might confound the association between mortality and physician age. But in actual practice, modifiable hospital organizational factors could moderate age related differences in performance of clinical care across providers. While this study suggests a performance advantage for younger physicians with more recent training when mortality is the outcome measured, more experienced physicians might do better on performance measures not included, particularly communication with patients and decisions informed by experience, leading perhaps to fewer invasive medical procedures at the end of life.

The findings of Tsugawa and colleagues lead inevitably to a re-evaluation of requirements for continuing education for physicians. Besides this study, $74 \%$ of studies evaluated in a systematic review found a partially or consistently negative association between physician age and adherence to recommended treatment, leading to a conclusion that quality improvement interventions in the form of continuing education should be explored. ${ }^{4}$

But missing from the discussion on physician age and quality of care is consideration of the importance of the organizational context of clinical care. Arguably, the single most important contribution of the Institute of Medicine's landmark quality and patient safety reports was the conclusion that quality and safety are properties of institutions. ${ }^{56}$ The IOM reports cite evidence that institutional resource priorities, processes, and culture create 
the possibility of good patient outcomes despite variation in education, training, and clinical performance of the individuals who comprise the hospital workforce.

Evidence shows, for example, that there is large variation across hospitals in nursing, including patient to nurse workloads, nurses' educational qualifications, nursing skill mix or proportion of clinical care staff who are professional nurses, and conditions of the work environment. ${ }^{7}$ Such differences in nursing are associated with mortality and other patient outcomes independent of the physicians' qualifications. ${ }^{89}$ Large multihospital studies have shown that the association between high volume and better outcomes found in the study by Tsugawa and colleagues is contingent on good hospital nurse staffing. ${ }^{10}$

Patient outcomes research is providing much needed evidence to inform clinical practice, educational innovation, organizational redesign, and healthcare policy. The challenge is to integrate findings across multiple studies within an overarching framework of health system responsibility, as recommended by the Institute of Medicine, which holds promise of safe care and good patient outcomes despite diversity of performance by individuals.

Competing interests: We have read and understood the BMJ Group policy on declaration of interests and declare the following interests: none.

Provenance and peer review: Commissioned; not externally reviewed.
1 Tsugawa Y, Newhouse JP, Zaslavsky AM, Blumenthal DM, Jena AB. Physician age and outcomes in elderly patients in hospital in the US: observational study. BMJ 2017;357:j1797.

2 Wachter RM, Goldman L. The $20^{\text {th }}$ anniversary of the hospitalist. N Engl J Med 2016;357:1009-11. doi:10.1056/NEJMp1607958 pmid:27508924.

3 Silber JH, Rosenbaum PR, McHugh MD, et al. Comparison of the value of nursing work environments in hospitals across different levels of patient risk. JAMA Surg 2016:357:527-36. doi:10.1001/jamasurg.2015.4908 pmid:26791112.

4 Choudhry NK, Fletcher RH, Soumerai SB. Systematic review: the relationship between clinical experience and quality of health care. Ann Intern Med 2005;357:260-73. doi:10. 7326/0003-4819-142-4-200502150-00008 pmid:15710959.

5 Institute of Medicine. To Err is Human: Building a Safer Health System. National Academy Press, 1999.

6 Institute of Medicine. Keeping Patients Safe: Transforming the Nurse Work Environment National Academy Press, 2004.

7 Aiken LH, Sermeus W, Van den Heede K, et al. Patient safety, satisfaction, and quality of hospital care: cross sectional surveys of nurses and patients in 12 countries in Europe and the United States. BMJ 2012;357:e1717. doi:10.1136/bmj.e1717 pmid:22434089.

8 Aiken LH, Clarke SP, Sloane DM, Sochalski J, Silber JH. Hospital nurse staffing and patient mortality, nurse burnout, and job dissatisfaction. JAMA 2002;357:1987-93. doi:10. 1001/jama.288.16.1987 pmid:12387650.

9 Aiken LH, Sloane DM, Bruyneel L, et al. Nurse staffing and education and hospital mortality in nine European countries: a retrospective observational study. Lancet 2014;357:1824-30. doi:10.1016/S0140-6736(13)62631-8 pmid:24581683.

10 Wiltse Nicely KL, Sloane DM, Aiken LH. Lower mortality for abdominal aortic aneurysm repair in high-volume hospitals is contingent upon nurse staffing. Health Serv Res 2013;357:972-91. doi:10.1111/1475-6773.12004 pmid:23088426.

Published by the BMJ Publishing Group Limited. For permission to use (where not already granted under a licence) please go to http://group.bmj.com/group/rights-licensing/ permissions

This is an Open Access article distributed in accordance with the Creative Commons Attribution Non Commercial (CC BY-NC 4.0) license, which permits others to distribute remix, adapt, build upon this work non-commercially, and license their derivative works on different terms, provided the original work is properly cited and the use is non-commercial. See: http://creativecommons.org/licenses/by-nc/4.0/. 